\title{
Digitalization in the Romanian Higher Education in the Present Digital Era
}

\author{
Maria Ciurea
}

\author{
Department of Economics Sciences, University of Petrosani, Petrosani, 332070, Romania \\ Email: mariamacris2011@yahoo.com
}

\begin{abstract}
The present challenge of the higher education system of Romania is the digital transformation, an action permanently preoccupying the government who is trying to find modern solutions to turn into practice the action domains foreseen by the National Strategy for the Digital Agenda, Romania 2020. Higher education digitalization is a transforming process influencing substantially all the higher education institutions' activities, from the development of new infrastructures, use of digital technologies for teaching and learning, research, support services, administration and communication, up to the students' and teaching personnel's need to develop new digital skills useful at present and future workplaces. In this context, the goal of this paper is to highlight by a theoretical approach the present situation of the Romanian higher education in the context of the digitalization phenomenon of the new digital era.
\end{abstract}

Keywords: digitalization, higher education, digital education, information technology, digital platforms,

coronavirus context, Romania

\section{INTRODUCTION}

At present, technology is what pushes mankind in its evolution and university is the most indicated place in the development of this technology and in the teaching process, to make it more attractive, and to prepare the young generation to join the labour market. The problem we have in front of us now is to use, in all universities, digitalization in teaching and let it become the tool used by every graduate, regardless of his domain of training. At present, in universities, the expectations of the present generation are related to digitalization and to the way the digitalization development is funded in higher education [1]. The future of society, democracy and government is digital, and Romania has all the necessary ingredients to be in the European and global frontline in this era of technological transformations. Digitalization of higher education is one of Romania's strategic goals which uses the successful models of other States that have already gone through this process [2,3]. Globally, the economy and the society will be influenced by the technological transformations, and the countries that do not set for themselves as priority the transversal integration of technology on all the levels of the economy and the society, simultaneously supporting and funding digital innovation, will not just lose opportunities, but will suffer significantly [4].

Internationally, there are several initiatives, generally private, in the domain of education. Each project brings something new, innovative, not all have the same impact nationally and institutionally, namely they are not generalized and extended for the entire higher education system in a country $[5,6]$. In numerous cases, this scaling on a national level cannot even be realized, because many of the projects launched use public blockchain systems, which, in most cases, do not respect the GDPR provisions, and suppose intricate business models.

A project developed by Romania together with the Executive Unit for the Funding of Higher Education, Research, Development and Innovation (UEFISCDI) is unique on the level of Europe by the technological approach used and its amplitude in perspective, and once finished will represent an important reference also for Government Blockchain Association (GBA) Romania and a possible model of study for the other almost 200 entities this association has in the world. Using blockchain to guarantee online the validity of the diplomas emitted by the higher education of Romania is a technological opportunity all the universities in Romania (public or private) will benefit from, without being conditioned by the existence of own hubs in the blockchain network of UEFISCDI. Any accredited higher education institution, issuing a graduation diploma and doing it in harmony with the juridical provisions, will be in the system and by smart contracts will introduce/transmit data in the system. The data introduced in the system are completely traceable and cannot be modified, as there can be only successive versions reflecting the evolution of the modifications in time.

Boston Consulting Group (BCG) is another entity helping the universities worldwide to adopt a multidirectional approach to develop their digital offers and approaches and increase their competitive advantage. Institutional 
learning has not changed much during the last two millennia, until the computer emerged [7]. Digitalization in the education process has the potential to change each facet of the academic experience, and this aspect is valid especially for higher education, which records an increased demand for innovative e-learning and online learning, modifying therefore the economy of education. Consequently, there is a series of dominant trends in the digitalization of higher education which change the competitive landscape, namely [8]:

$\checkmark$ individualization of education. Digital education permits a greater flexibility and a greater personalization in what, how and where the lectures are delivered, creating in this way a faster and more relevant feedback;

$\checkmark$ democratization of education. The large number of new students expected to join higher education in the nearest future and an increased prosperity will allow higher education digitalization to be more scalable and accessible;

$\checkmark$ digitalized students. Today's students are the digital natives used to information technology, who want to benefit of the time and location of their choice;

$\checkmark$ exponential technological advances. Digital education is promoted by the new capabilities in mobile devices, cloud delivery systems, streaming video and other broadband applications and education management systems;

life-long learning. Higher education is no longer available exclusively for traditional students who can participate in lectures according to the ordinary schedule. Digital education offers non-traditional students, including full-time workers, single parents or career-change seekers, convenient access to higher education in different stages of their life;

$\checkmark$ changes in the labour force. Digitalization and automation at the workplace call for new and continually growing skills. Consequently, employers ask universities to offer to their employees more opportunities of access to a continual and convenient education.

All these trends have numerous implications for universities as they rapidly go fast forward regarding their digital education capabilities. At the same time, universities can use digital education to win new opportunities and supplementary resources to carry out a more innovative research, serving to improve the trend and competitiveness of the teaching institutions [9, 10]. For this reason, the successful BCG approach, adopted by several renowned international universities, focuses on a series of aspects, such as:

- digital education and research. Universities need to apply a large series of digital initiatives, not just online classes. They include digitalized pedagogy and support for the education and monitoring systems; scalable online education realizing a large distribution; accrediting and dynamic examination; research development using digital tools, digital data access, digital communication and global transparency.

- strategies, operations and partnerships. Universities need to adopt digitalization as part of the general strategy to transform the existing structures and processes, to apply the digital changes and permit innovation and entrepreneurship. These need to adapt business models able to assure increased quality and efficiency and encourage collaboration in the conclusion of partnerships with other universities. [11, 12].

Although digital transformation offers numerous opportunities, at present, the greatest risk is for the society not to be prepared enough for such an evolution [13]. If higher education is among the pillars of the economic growth and of the EU inclusion, then an important task is to prepare the citizens to take advantage maximally of these opportunities and face the challenges of a globalized, interconnected and fast-evolving world.

\section{RESEARCH METHODOLOGY}

For the present paper, we have analysed several studies and papers from this domain. This research is qualitative, investigating the present situation of the evolution of digitalization in higher education. This approach has called for objective observation and a certain reasoning to highlight the influence of using online platforms as means of digitalizing the system have on higher education. As indirect research technique we have used documentation analysis, without turning to numerical data. The theoretical information was taken from specialized papers and studies published in various journals and proceedings of national or international conferences, books, websites of institutions relevant in the domain under analysis, such as: National Education Ministry, Executive Unit for the Funding of Higher Education, Research, Development and Innovation, Romanian Agency for Higher Education Quality Assurance (ARACIS).

\section{RESULTS AND DISCUSSION}

\subsection{Influence of on-line platforms in the digitalization of the Romanian higher education}

Basically, digitalization is the process of conversion of analogical information in a digital format. In a much larger context, much larger, digitalization is defined as the social transformation triggered by the massive adoption of digital technologies to generate, process and exchange information [14, 15]. It uses the collateral effects resulting from their use: common platforms to develop applications, e-government, e-commerce services, social networks, and on-line information availability. The progress in the digital domain has brought new challenges for the students and the teaching staff. The algorithms used by the social communication platforms and news portals can strongly amplify biased attitudes and fake news, and data protection has become a major concern in the digital society $[16,17]$. Daily exposure to digital data largely created by impenetrable algorithms creates clear risks and requires 
more than ever a critical thinking and the capacity to interact positively and competently in the digital environment. We are faced with a permanently changing need of media literacy, extremely varied digital, security, safety and confidentiality skills, but their obtaining remains a challenge for the greatest part of the higher education system $[18,19]$.

On the level of the European Union (EU), an online platform has been created to support higher education institutions (HEI) in the use of digital technologies. This platform acts as a hub for the existing European platforms, national and regional, dealing with online learning, combined/virtual mobility, online campuses and good practices exchange. The need for such a platform has been imposed by the fact that the digital transformation can bring a series of benefits for higher education institutions, such as [20]:

$\checkmark$ improving the quality and relevance of learning and teaching.

$\checkmark$ higher education becomes more accessible for a larger array of students.

$\checkmark$ creation of connections between higher education institutions, research institutions, employers and the larger community.

facilitation of internationalization.

Such an online platform has access to the existing online platforms and will improve the dissemination of good practices to all the education institutions. At the same time, this will make available for HEI materials for: training the academic personnel on innovative pedagogies and curriculum design; materials and good practices exchanges; mixed and digital learning, and mixed mobility; collaboration between higher education institutions and employers [21].

Many national platforms on these topics can be found in the member States; some have a national perspective, others, transnational. This action has increased also in the higher education system of Romania, where there are numerous platforms used in the digitalization of the activities from the system. These are presented subsequently.

Integrated Educational Register (REI) is a platform offering access to the educational trajectory of a person, by interconnecting the management system from the educational sector, also with the connected management systems, by a cloud-type solution. The national platform REI is managed by the National Education Ministry (MEC) via UEFISCDI, a public institution with juridical personality. REI integrates as well one module for updating and generating higher education catalogues, assuring the uniqueness of the catalogues used on the level of the educational system [The Integrated Informatic Education System of Romania (SIIIR), The Unique Matriculation Register (RMU), The Romanian Higher Education Quality Assurance Agency (ARACIS), etc.]. At the same time, it permits the generation of reports and statistic indicators answering the benchmarking requests on a national and international level. Simultaneously, this platform contributes to: the improvement of the higher education management, formulation of public educational policies, assuring standardization and data consistency in the higher education system and increased transparency level for higher education information [22]. At the same time, it assures the administration of the evaluation process for the doctorate files handed over to the National Council for the Certification of Higher Education Titles, Diplomas and Certificates (CNATDCU) to validate doctoral theses and formulate proposition for granting/not granting the title of doctor. To facilitate the information exchange and the analysis of the correlation of the educational offer with the labour market demands, it is inter-operable with the Platform Students, Graduates and Labour Market (SAPM). Also, by it, one can access a unique national database, comprising detailed information on the students and higher education graduates from Romania.

Based on concrete and permanently updated data, reports are generated, which can substantiate a large array of processes, from adaptation of the educational offer, on the university level, to development of policies in the domain, on a national level. At the same time, the aim is to obtain a real image of the human capital developed by the higher education: the number of participants and graduates, on cycles and domains of study, tuition level and form of funding, these data contributing to avoiding reporting errors and to discouraging diploma forgery.

The student, and respectively the graduate, has real-time access to information on the university trajectory, has the opportunity to participate to different studies by means of which he can communicate to the university representatives and central authorities his opinions about the specializations followed and their professional development. Therefore, the resulting data will allow universities to periodically analyse their programmes of studies in point of their attractiveness, but also of their efficiency in training students for the labour market.

The platform has been developed as an instrument of electronic government, allowing the standardization of the terminology specific of higher education in harmony with the general criteria of organization and development of higher education. Central institutions have safe access to real and consistent data from the higher education system and to their history, allowing to identify possible recording errors.

The platform allows consulting statistics and reports corresponding to reference moments in time, but also dynamic evolution, both for each university, and for the entire education system. Moreover, the reports can concern process-type aspects, regarding the universities' educational offer, and result-type aspects, looking at the students' evolution after graduation.

By means of REI one can access RMU (The Unique Matriculation Register), a platform assuring the integrated management of the data concerning the state-run and private university students from Romania for all the academic years and all the study cycles, constituting a continual collection and centralization approach, to increase the efficiency of the administrative activity and improve the capacity to substantiate institutional strategies and national policies in this domain. According to the provisions of the National Education Law no. 1/2011, Art. 
201, RMU is the main support for the implementation of The Unique Matriculation Register of the Universities of Romania (RMUR). The use of this platform has in view the following aspects:

$\checkmark$ increasing the efficiency and fluency of the process reporting the universities to the various central institutions;

$\checkmark \quad$ obtaining a real image regarding all the students from the higher education system (the number of participants and graduates, the population enrolled in higher education, on cycles and domains of study, level of tuition and form of funding; real and consistent data regarding the matriculation and graduation of a student, financial status, student mobility and internship etc.)

$\checkmark$ generation of system indicators (performance, funding, management, quality).

Another platform used is the National Platform Collecting Statistical Data for Higher Education (ANS), representing an integrated informational system, developed in modules, compatible with the European data collection systems, dedicated to the higher education of Romania, reuniting the main statistical data on higher education accessible to all the actors interested.

The Platform Study in Romania (SIR) promotes the Romanian higher education globally, contributing to attracting national and international students in programmes of study from the educational offer of the Romanian universities. Among the platform's objectives are: worldwide;

promoting the Romanian higher education

- increasing the awareness regarding Romania's status as destination of study in the European Union;

- increasing the visibility and promoting the educational offer of the universities of Romania in the international environment;

- attracting international students in programmes of study from the educational offer of the Romanian universities;

- $a$ better information of the Romanian students concerning the educational offer from Romania

The Platform Students, Graduates and Labour Market (SAPM) is a library of tools for developing and implementing studies monitoring the professional insertion for higher education graduates. By the safe access to these research tools is supported the effort of the universities in Romania to develop and offer programmes of study relevant for the labour market. The Universities in Romania benefit of:

$\checkmark$ centralized online management of the communication with students and graduates, including the online transmission of the invitation to participate to various studies;

$\checkmark$ collection of opinion data via online nationally standardized questionnaires;

$\checkmark$ possibility to draw inter - institutional comparisons and elaborate evaluations of the performance level based on the indicators of insertion of the graduates on the labour market, online data analysis module.
The Platform Engage in the Romanian Research Infrastructures System (ERRIS) has been created to support the coordinators of the public/private research infrastructures in Romania and those wanting to benefit of the services offered by these infrastructures, stimulating the collaboration and participation to specialized national and international networks of the scientific community from Romania. Developed as a social network, the platform ERRIS is a Facebook of things in which the research infrastructures are actors, having the possibility to make known their services on a market as large and as diversified as possible. By realizing this platform, an answer is given, at the same time, to the actions needed to internationalize the national research, development and innovation system, in harmony with the National Research, Development and Innovation Strategy 2014 2020.

To facilitate the evaluation process for the research projects funded by UEFISCDI and other similar agencies and reunite the national and international experts in research, innovation and entrepreneurship, the platform BrainMap has been developed. In the framework of the online community, one can find Romanian and foreign evaluator experts, applicants in the PNCDI II and PNCDI III contests, directors of funded projects, and entrepreneurs with innovation activity, being also used to select the consultative councils' members for research and higher education [22].

Now, BrainMap is going through an ample development process aiming to accomplish not just a support function for the evaluation of research projects, but to create a community for the actors involved in research, innovation and entrepreneurship activities and become a unique point of access to information relevant for research and innovation, for example: publications, patents, projects, calls to competitions, specific expertise, research infrastructures.

We consider that the use of such platforms are opportunities and challenges for the evolution of the phenomenon of higher education digitalization

\subsection{The digitalization of the Romanian higher education in the coronavirus context}

Following the present situation, which has disrupted many activity domains and interrupted the educational process, the Romanian IT\&C sector wants to support the institutions involved by offering for free efficient communication and collaboration solutions, already used currently on the market. For instance, Cisco Systems supports this process and provides pro-active video, voice and text collaboration solutions, safe connection by VPN and multi-factor authentication, free for the higher education institutions interested and for their employees. The adaptation to the new situation of crisis has imposed new measures, implementable rapidly, which shall not hinder the activities and teaching process. In the coronavirus context, the universities in the Romanian 
university system have decided to take their teaching activities to the online environment, opening perspectives to modernization for them. Consequently, the university education system wants to get involved in the formation of a basis of technical and soft resources dedicated to the educational process on the national level. It is a fact that there are many complex tools, dedicated to the efficient learning and structuring of the teaching processes, such as the platforms offered by Google, and now in front position are the online interaction tools (videoconference systems, online survey-type systems, but also communication and written interaction facilities). Becoming important for the development at a distance of the teaching activities, especially during a crisis, like the one triggered by the coronavirus spreading, the online infrastructure includes elearning platforms available in many universities for teachers and students, in all the zones and functionalities of the university structure. For instance, university education has an integrated system of specialized platforms for online learning, adapted to the specific of each institution, as the adapted platform Moodle, but also the classical Google Classroom or Edmodo and Google Meet or Skype for Business for videoconferences. All these tools permit the transmission of the course support and bibliographic resources online, electronic communication between students and teaching staff, both by private messages and forum messages, organization of videoconferences, setting of educational tasks for students, uploading homework and projects, evaluating them and giving feedback or undertaking other teaching-learningevaluation activities [23]. Even if no one can be happy at the restrictions imposed by the coronavirus spreading crisis, even if getting out of the comfort zone of the unmediated interactions from the classes or laboratories is not very simple, it is good to see as well the positive side of this phenomenon we are going through, consisting in the need to extend as fast as possible the use of skills and habits related to online educational platforms, in the present context of the university environment. At the same time, the digitalization of the administrative procedures is also a must, in the present situation, which requires an adaptation to the crisis.

The present crisis will have a major negative impact on the universities from the whole country, as they will not be able to have new students in the academic year 2020-2021 (except for the candidates joining a second faculty, those who have not enrolled at a faculty although they have passed their baccalaureate examination, or those who have interrupted their studies and want to resume them), which will require them to choose one of the following scenarios:

$>$ 1. the academic year is not frozen, accepting the situation that will be generated by the impact of the model of funding per student, a situation in which the government will need to support financially the situation of these institutions, to avoid firing or optimizing the academic teaching staff by funding the universities through a reviewed budget;

$>$ 2. the academic year is frozen, but the impact will hit the business environment, which will not be able to benefit in totality of the new generation of graduates on a labour market already suffering from a deficit of skills. Equally, it is hard to imagine the labour market after the economic crisis COVID-19, so that it is possible for the market to find a way to become normal again naturally. Such a decision will equally affect the public institutions hiring graduates to replace the personnel who has reached retirement

Following the constraints determined by the coronavirus crisis, the extensive use of the digital environments will constitute a factor in the educational process to transform these institutions into the digital universities of the future.

\section{CONCLUSIONS}

The digital revolution will continue to radically change the way the citizens are living, working and studying. The spirit of innovation and entrepreneurship in education and training should be stimulated and supported by a clear political will and by efforts meant to bring innovation in everyone's life. There is the need to share, to discuss and to promote, and, where possible, to spread the innovating practices. The professionals from the domain of education, who usually do not know very well what is experimented in other places, sometimes not even in the framework of the same institution, should have easier access to a series of concepts, instruments, methods, processes, to systemic thinking and to conceptual thinking.

In the context of the new approaches that also include the digital learning environment, by the digital participation of both teaching staff and students but also of other relevant types of education, the parties concerned should be continually interested in updating and redesigning the courses and curricula, and self-aware of the need for constant learning for digital literacy, which will largely contribute to the transformation of the digital universities.

At present, the great universities have opened their gates in the online domain, in the sense of extending the access to education for anyone, regardless of his geographic area, age, biological gender, race, ethnicity, Massive Open Online Course has emerged, as online, free variant of delivery of learning contents, allowing the enrolment of an unlimited number of participants, with various aims, interests, knowledge and skills, to help create a lifelonglearning community.

The future of the Romanian higher education in the digital era calls for a successful implementation of aspects regarding:

- assuring free access to education resources, including by implementing online platforms and learning tools, facilitating the teaching process and being as accessible and easy to use as possible. An eloquent example in this sense being the online libraries, by which various alternative teaching methods can be implemented, but also other tools able to increase the degree of trust between the students and the teaching staff and the transparency of the evaluation process. At the same time, it becomes possible to create an inclusive environment for various categories of students, for instance students with 
[4] G. Grosseck, L. Malita, R. Bran, "Digital University - Issues and Trends in Romanian Higher Education", Brain-Broad Research in Artificial Intelligence and Neuroscience, 10(1), 2019, 108-122.

[5] M, Macris, V. Ciurea, Considerations about the priorities in the field education and training in Europe in the current economic context", Internal Auditing \& Risk Management, 8(3), 2013, 1-13.

[6] M. Măcriș, C. Ioanăș, Considerations on the Implementation of Post-Bologna Process at the Level of a State University Using the SWOT Analysis, in: Proceedings of The 25th International Business Information Management Association Conference: Innovation Vision 2020: From Regional Development Sustainability to Global Economic Growth, Amsterdam, Netherlands, 2015, pp.3078-3088.

[7] L.K. Gurieva, R.I. Btemirova, M.A. Kovaleva, University 4.0: new education technologies in the digital economy, Advances in Economics, Business and Management Research (Atlantis Press), vol 105, Proceedings of the Ist International Scientific and Practical Conference on Digital Economy (ISCDE), 7-8 November, 2019, Chelyabinsk, Russia, pp.494-499. DOI: https://doi.org/10.2991/iscde-19.2019.94

[8] F. Rampelt, D. Orr, A. Knoth, Bologna Digital 2020. White Paper on Digitalisation in the European Higher Education Area. Berlin: Hochschulforum Digitalisierung, 2019 , https://www.researchgate.net/publication/333520288_B ologna_Digital_2020_White_Paper_on_Digitalisation_i n_the_European_Higher_Education_Area

[9] M. Ciurea, M. Man, The Role of Key Actors in the Reform of the Higher Education in Romania to Achieve the Objectives of the European Strategy in Education", in: Proceedings of 27th IBIMA Conference on Innovation Management and Education Excellence Vision 2020: from Regional Development Sustainability to Global Economic Growth, Milan, Italy, 2016, pp. 2632-2642.

[10] O.L.Begicheva, T.A Beregovskaya, S.A. Grishaeva, Online Education in Higher Education, Advances in Economics, Business and Management Research, vol. 81, Proceedings of the 1st International Scientific Conference "Modern Management Trends and the Digital Economy: from Regional Development to Global Economic Growth" (MTDE), Yekaterinburg, Russia, 14-15 April, 2019, pp. 698-701. DOI: https://doi.org/10.2991/mtde-19.2019.142 
[19] M. Macris, M. Man, The design of the romanian education in the context of knowledged - based development, Annals of the University of Craiova, Economic Sciences Series, 2 (42), 2014, 119-126.

[20] J. Conrads, M. Rasmussen, N. Winters, A. Geniet, L. Langer, Digital Education Policies in Europe and Beyond: Key Design Principles for More Effective Policies. Redecker, C., P. Kampylis, M. Bacigalupo, Y. Punie (ed.), EUR 29000 EN, Publications Office of the European Union, Luxembourg, 2017, DOI:10.2760/462941, JRC1093

[21] O.V. Potasheva, M.V. Kuzmenko, M.I. Plutova, The effective use of digital technologies in education: positive experience of regional innovation platforms, Advances in Economics, Business and Management Research, vol. 81, Proceedings of the 1st International Scientific Conference "Modern Management Trends and the Digital Economy: from Regional Development to Global Economic Growth" (MTDE), Yekaterinburg, Russia, 14-15 April, 2019, pp. 688-693. DOI: https://doi.org/10.2991/mtde-19.2019.140

[22] Information platforms, Available at: https://www.edu.ro/, https://uefiscdi.gov.ro/, https://www.brainmap.ro/ [Accessed on 08.03.2020]

[23] M. Ciurea, Considerations on the influence of digital technology regarding education in Romania, Advances in Economics, Business and Management Research, vol. 81, Proceedings of the 1st International Scientific Conference "Modern Management Trends and the Digital Economy: from Regional Development to Global Economic Growth" (MTDE), Yekaterinburg, Russia, 14-15 April, 2019, pp. 639-643. DOI: https://doi.org/10.2991/mtde-19.2019.129
[17] R. Bejinaru, Impact of Digitalization on Education in the Knowledge Economy, Management Dynamics in the Knowledge Economy, 7, 367-380. DOI: 10.25019/MDKE/7.3.06

[18] M. Ciurea, The Digital Economy in Romania: Theoretical Approaches and the Current State of Development in the Context Imposed by the European Union, Advances in Economics, Business and Management Research (Atlantis Press), vol 105, Proceedings of the Ist International Scientific and Practical Conference on Digital Economy (ISCDE), 7-8 November, 2019, Chelyabinsk, Russia, pp.539-545. DOI: https://doi.org/10.2991/iscde-19.2019.104 